\title{
Navorsingsbriewe
}

\section{'n Vergelyking van die lipiedkomponente van springbokvleis met die van beesvleis en die verwante belangrikheid vir aspekte van die menslike gesondheid}

\author{
Ontvang 25 Mei 1998; aanvaar 2I Januarie 1999
}

\begin{abstract}
Alsstract
A comparison of the lipid components of springbok meat with those of beef and the related importance on aspects of health Coronary heart diseases are today considered an epidemic and dieticians suggest a drastically reduced intake of saturated fatty acids. The fatty acid composition of springbok meat was compared with that of beef. The total saturated fatty acid content of springbok meat was significantly lower than that of beef Consumers are increasingly concerned about the quantity of their daily intake of diet fat. This is an indication that springbok meat has the potential to be successfully positioned in relation to health related market segments
\end{abstract}

\section{INLEIDING}

Eksponensiële bevolkingsaanwas vereis dat moderne landboutegnieke en hoë-opbrengs genetiese verbetering die kwantitatiewe aspekte met betrekking tot die aanbod van voedsel ondersoek, maar wat van die kwalitatiewe aspekte?

Die verbruiker word vandag met verskeie voedselverwante gesondheidsprobleme gekonfronteer. Geneeskundiges en voedingskundiges is oortuig dat die dieetgewoontes van die Westerling die risiko vir hartvaatsiektes, hipertensie en sekere tipes kanker verhoog. Hierdie gesondheidsprobleme het slegs die afgelope eeu ontwikkel met enorme gesondheidskoste en verreikende ekonomiese implikasies in Westerse lande. ${ }^{1}$ Die verbruikersweerstand wat die rooivleisbedryf in die Verenigde Koninkryk ervaar het, het ekonomiese gevolge (beesvleisverbruik in die Europese Unie het in 1996 met $11 \%$ gedaal teenoor 1995) wat direk verband hou met verbruikers se persepsies van die kwaliteitseienskappe van voedsel. ${ }^{2}$

Die invloed van dieetvet op plasma-cholesterolvlakke kan deur die hoeveelheid en tipe vet in die dieet beïnvloed word. ${ }^{4}$ Daar is ook 'n verband tussen die hoë totale cholesterolvlakke in die plasma en koronêre hartvaatsiektes.

'n Laevetdieet word deur die Amerikaanse Hart Vereniging aanbeveel om die risiko vir koronêre hartvaatsiektes te verlaag. ${ }^{1}$ Studies oor dieetvette en die insidensie van koronêre hartvaatsiektes dui daarop dat bevolkings met relatief min hartvaatsiektes diëte volg wat laag in totale vette en versadigde vette is. ${ }^{5}$

Gesondheidsprobleme wat met die Westerling se dieet verband hou, is afwesig by die weinig oorblywende jagter-versamelaarbevolkings. ${ }^{\circ}$ Nieteenstaande hulle hoë daaglikse inname van dierlike proteïen ( $788 \mathrm{~g}$ wildvleis) is die vetinname relatief laag in vergelyking met dié van die Westerling. Wild het as gevolg van hulle weigewoontes maer vleis, in teenstelling met 'n hoër vetinhoud van die huidige gedomestikeerde vleisbronne wat met graanprodukte in voerkrale gemes word. ${ }^{6}$ Wildsvleis is laer in versadigde en hoër in poli-onversadigde vetsure as graangevoerde beeste. ${ }^{7}$ Hierdie eienskap van wildsvleis mag moontlik toegeskryf word aan wild se genetiese samestelling.

Maer vleis kan deel vorm van 'n lipiedverlagende dieet. In studies op vrylewende mans met genetiese hoë plasmacholesterol, is plasma totale cholesterolvlakke verlaag deur maer vleis by hulle normale dieet in te sluit. ${ }^{8}$

Dieetriglyne, opgestel deur die Departement van Nasionale
Gesondheid in 1992, ${ }^{9}$ beveel aan dat totale vet- en versadigdevetinnames verlaag moet word om die risiko vir koronêre hartvaatsiektes te verlaag. Hierdie projek het ten doel om deur middel van analitiese ondersoeke die kwaliteitseienskappe van springbokvleis te bepaal.

\section{METODES}

Verteenwoordigende monsters $(10 \mathrm{~g})$ rou gemaalde vleis van vyf snitte (blad, bors/lies, nek, lende en boud) springbokvleis wat lugdig verpak en gevries is, is vir vetsuursamestelling, totale lipiede en cholesterol ontleed. Elke snit is met die vel aan teen $4{ }^{\circ} \mathrm{C}$ vir 7 dae verouder en daarna by $-20^{\circ} \mathrm{C}$ gevries. Springbokvleis is van die Irene Vleisbedryfsentrum verkry en die karkas wat vir die ontleding gebruik is, is op 'n ewekansige wyse gekies. 'n Jong volwasse ram van 80 weke oud met 16 horingringe is vir die ontleding gebruik. Die finale $\mathrm{pH}$ van die vleis gemeet in die $M$. Longissimus thoracic-spier op 34 ure na dood was $5,81 .^{3}$

Die cholesterol en vetsure is deur middel van gasvloeistofchromatografie in die laboratoriums van die Mediese Navorsingsraad (MNR) in Tygerberg gekwantifiseer. Die vetsure is deur chloroform-metanol ge-ekstraheer en deur gaschromatografie geanaliseer. Die totale cholesterol in chloroform-metanol-ekstraksies is deur gasvloeistofchromatografie, deur middel van 'n Varian Vista gaschromatograaf bepaal. Stimasterol (Merck katalogus no. 3743) is as die interne standaard gebruik.

Lipiede is ge-ekstraheer en ' $n$ kalorimetriese metode is gebruik om die totale lipiedinhoud te bepaal.

\section{RESULTATE}

Die bevindings van die ontledings op springbokvleis is met soortgelyke ontledings op beesvleis vergelyk. ${ }^{7}$ Die ontledings van springbok- en beesvleis is op verskillende tydperke uitgevoer, maar gestandaardiseerde analitiese metodes deur die Mediese Navorsingsraad te Tygerberg is vir die ontledings gebruik

Die samestelling $(\mathrm{mg} / 100 \mathrm{~g})$ van vetsure in springbokvleis en die moontlike uitwerking op serumcholesterol word in tabel 1 aangetoon. Uit tabel 1 kan afgelei word dat vetsure met serumcholesterol-verlagende en neutrale eienskappe drievoudig soveel is as die vetsure met serumcholesterol-verhogende eienskappe. Die uitwerking van verskillende vetsure op serumcholesterolvlakke word deur verskeie outeurs opgesom. ${ }^{4}$

Figure 1-9 gee 'n opsomming van die vergelykings wat tussen 
Tabel 1 Samestelling van vetsure $(\mathrm{mg} / 100 \mathrm{~g})$ in springbokvleis en die moontlike uitwerking op serumcholesterol

\begin{tabular}{cccc}
\hline Vetsure met & $\begin{array}{c}\text { Vetsure met } \\
\text { serumcholesterol- } \\
\text { serumcholesterol- } \\
\text { verlagende en } \\
\text { neutrale } \\
\text { eienskappe }\end{array}$ & $\begin{array}{c}\text { Vetsure se } \\
\text { uitwerking op } \\
\text { eienskappe }\end{array}$ & $\begin{array}{c}\text { serumcholesterol } \\
\text { nog onbekend }\end{array}$ \\
\hline Blad & 398,54 & 1244,36 & 40,01 \\
Bors en lies & 577,76 & 1565,58 & 44,78 \\
Nek & 450,07 & 1312,35 & 32,88 \\
Lende & 427,42 & 1292,48 & 35,58 \\
Boud & 343,02 & 1099,49 & 22,09 \\
Totaal & 2196,81 & 6514,26 & 175,34 \\
\hline
\end{tabular}

dieselfde snitte van springbok- en beesvleis getref is. Uit die figure kan afgelei word dat springbokvleis laer hoeveelhede ( $\mathrm{g} / 100 \mathrm{~g}$ ) versadigde vetsure as beesvleis het, veral miristien- en palmitiensuur wat serumcholesterol-verhogende eienskappe besit. 'n Hoe konsentrasie $(\mathrm{g} / 100 \mathrm{~g})$ aragidoonsuur, 'n hoogpoli-onversadigde vetsuur met serumcholesterol-verlagende eienskappe, is in springbokvleis gevind. Visueel kan afgelei word dat die cholesterol- en veral die totale vetinhoud van springbokvleis laer is as die van beesvleis. Verder is daar hoogpoli-onversdigde vetsure in springbokvleis gevind ( $\mathrm{C} 20: 5 ; \mathrm{C} 22: 4,6)$ wat afwesig was in beesvleis.

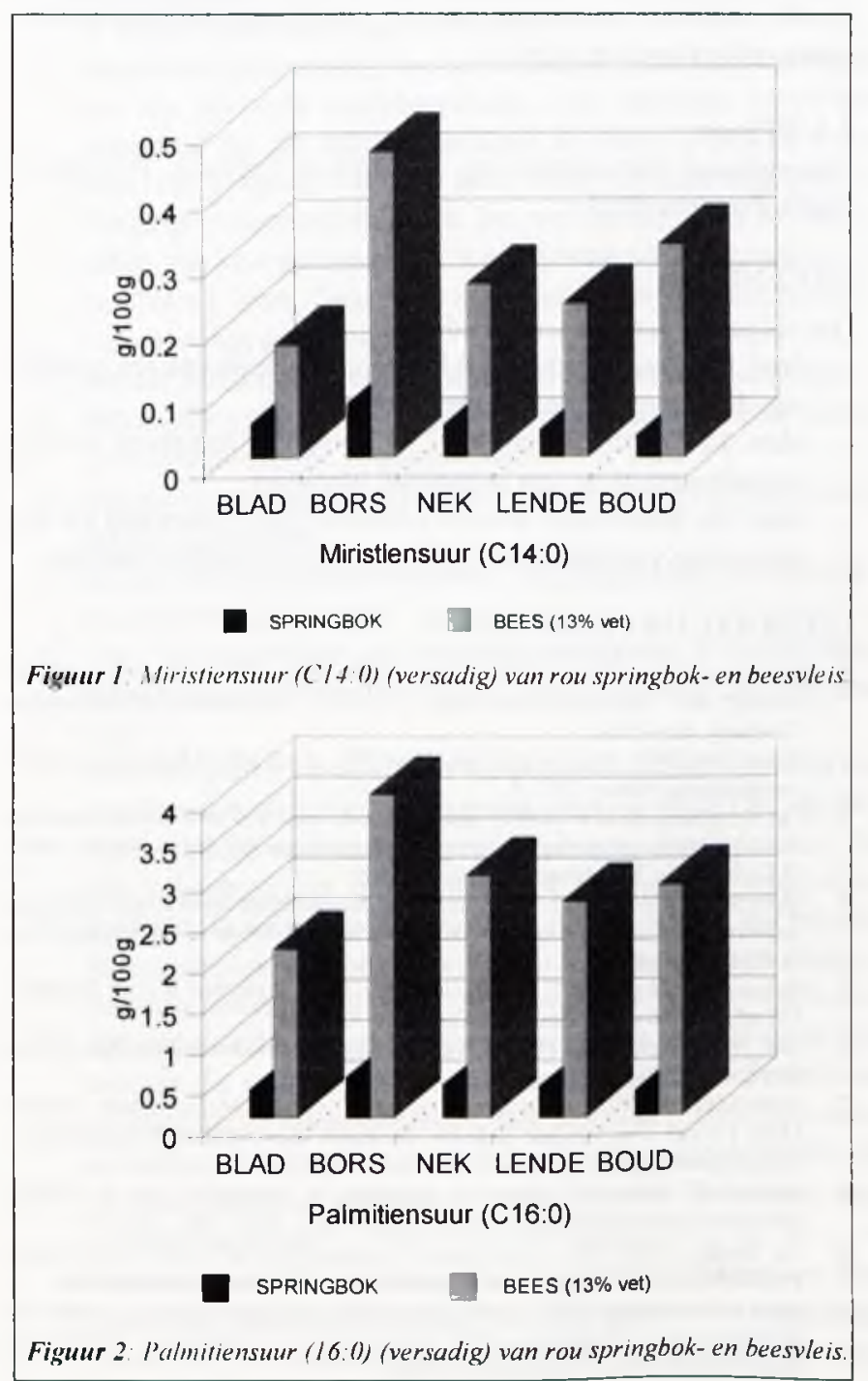

Die volgende verskille tussen die kruisskyf van bees en die boud van springbok is van gesondheidsbelang vir die verbruiker:

- die opvallend lae totale lipiedinhoud van springbokvleis (vier maal laer as bees);

- die laer inhoud van palmitoleiensuur (C16:1) in springbokvleis, 'n mono-onversadigde vetsuur, veral as 'n mens in

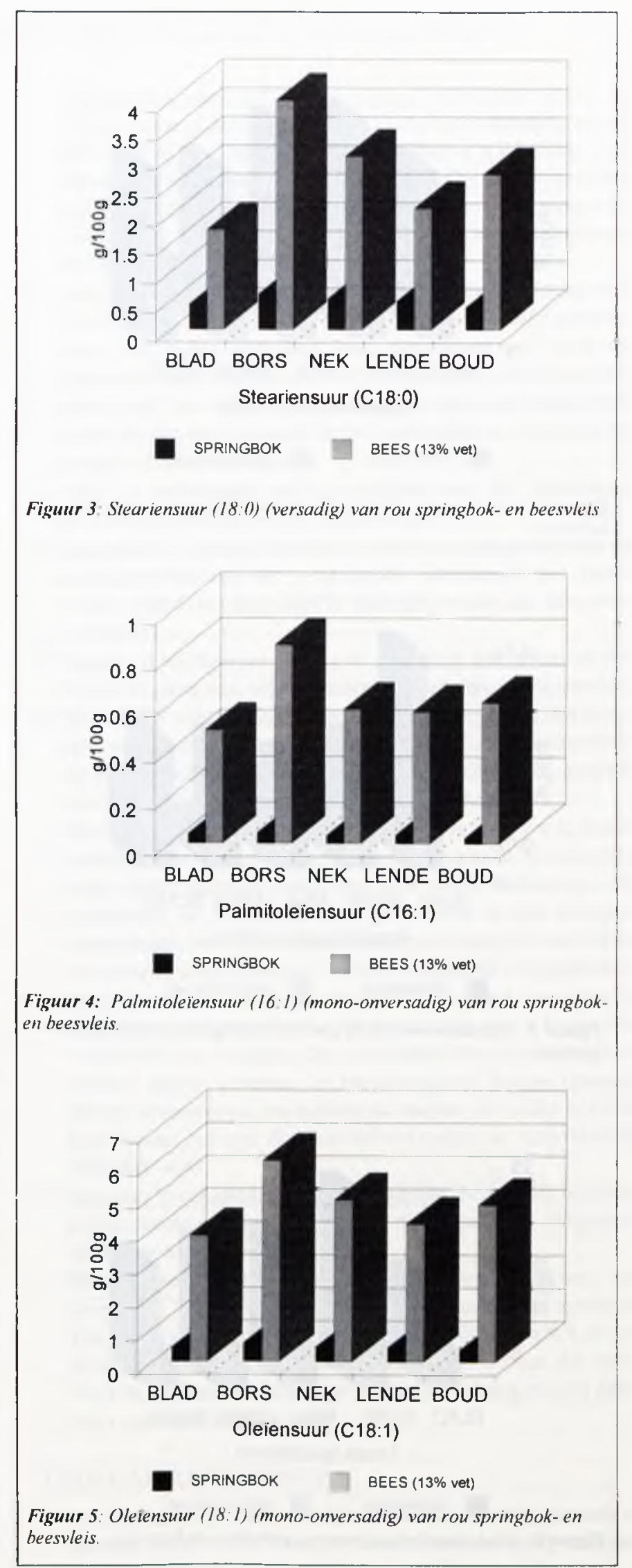


gedagte hou dat mono-onversadigde vetsure tans net so aterogenies beskou word as versadigde vetsure;

- die voorkoms van hoër hoeveelhede aragidoonsuur (C20:4) in springbok is belangrik, aangesien dit 'n bekende feit is dat dit 'n voorloper van prostaglandien is; en

- die teenwoordigheid van die hoër onversadigde vetsure in springbokvleis.

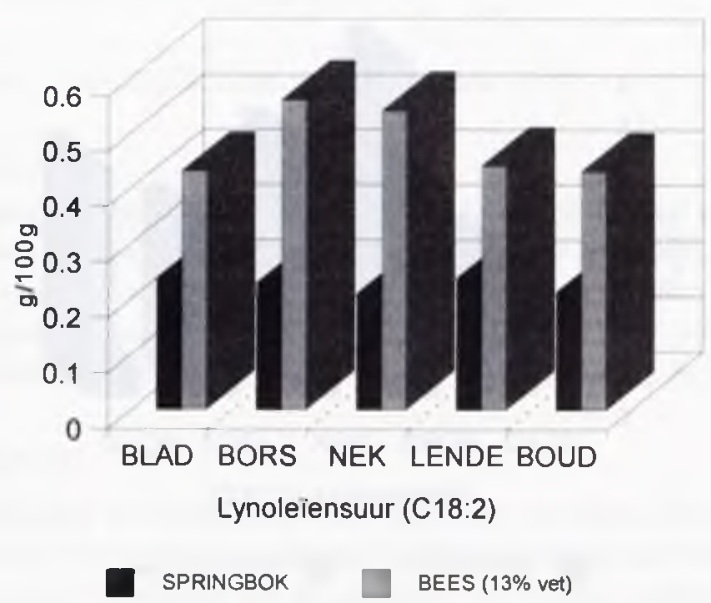

Figuur 6: Lynoleiensuur (18:2) (poli-onversadig) van rou springbok- en beesvleis.

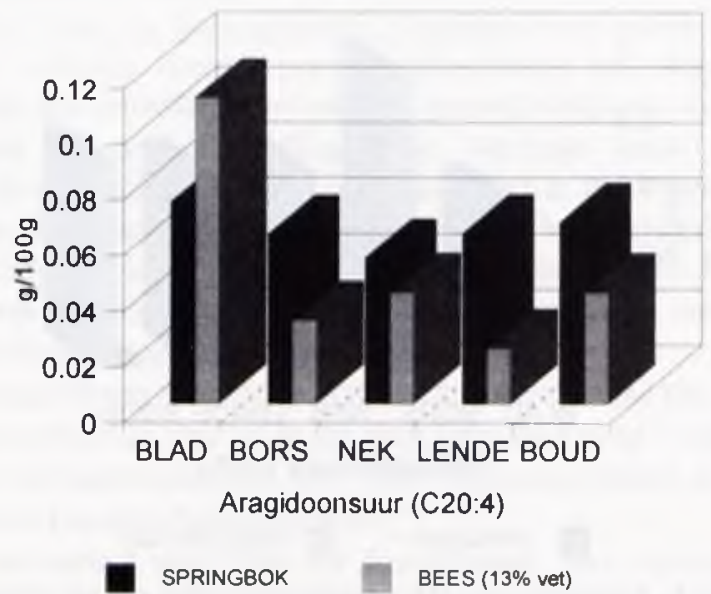

Figuur 7: Aragidoonsuur (20:4) (poli-onversadig) van rou springbok- en beesvleis.

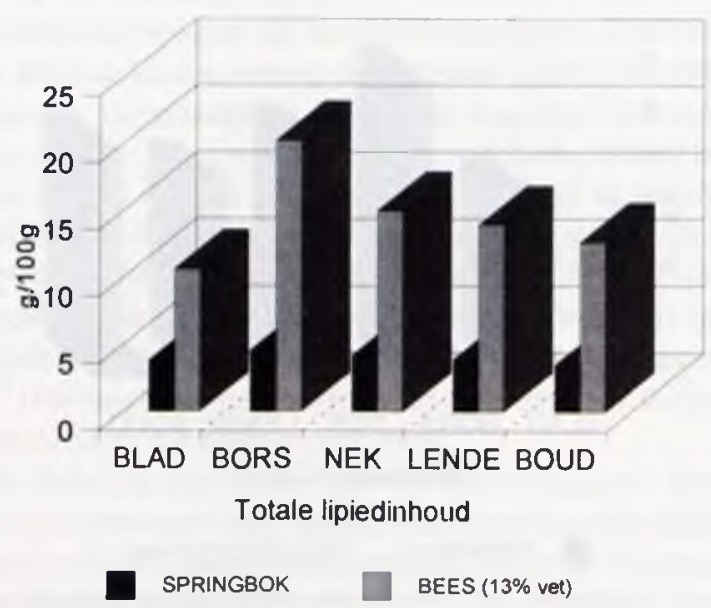

Figuur 8: Tolale lipiedinhoud van rou springbok- en beesvleis.

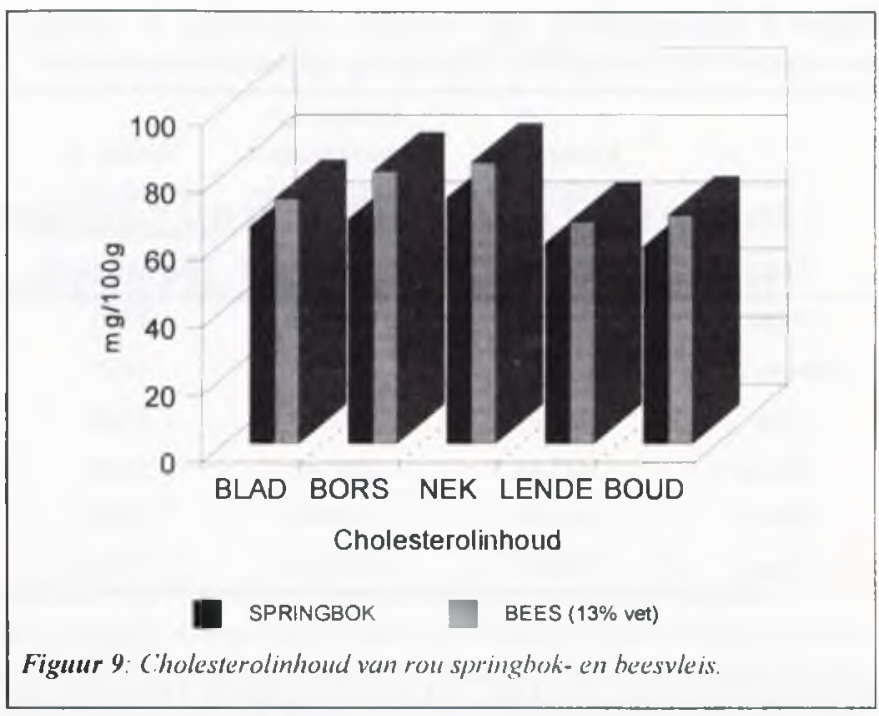

Dit blyk dus dat springbokvleis wel gesondheidsvoordele bo die van beesvleis kan hê, veral as in ag geneem word dat die beesvleis waarmee die springbokvleis vergelyk is, 'n karkas met 'n 13\% vetinhoud was, wat in die laagste vetinhoudkategorie van gekommersialiseerde beesvleis ressorteer. Verder het die springbokkarkasse wat in die Noord-Kaap geoes is $(n=90)$ geen onderhuidse vet getoon nie. ${ }^{10}$

Die kommersiēle bemarking van wildvleis is nog in sy kinderskoene en verskeie kwaliteitseienskappe van wildsvleis behoort nog in die toekoms ondersoek te word. Aanvullend tot hierdie analitiese ondersoek behoort langtermyn kliniese ondersoeke ook geloods te word.

\section{J.J. Viljoen}

Departement Natuurbewaring, Technikon Pretoria, Privaatsak X680, Pretoria, 0001

\section{ERKENNING}

Die volgende persone word bedank

- Prof. H.F Joubert en dr. J.P Kotzè vir hulle insette ten opsigte van die interpretasie van die resultate.

- Mev. H. Schönfeldt en dr. D.M Janse van Rensburg vir die beskikbaarstelling van toepaslike literatuur.

- Mnr. De Wet Marais van die Mediese Navorsingsraad vir die uitvoering van die lipied-, vetsuur-, en cholesterol-analises.

\section{LITERATUURVERWYSINGS}

1. Robinson, C H, Lawler, MR. Chenoweth. W L.. Garwick, A E. (1986) Normal and Therapewic Nutrition. Th ed.c. 38 (Macmillan Publishung Company, NewYork)

2. Butler, D. (1997). Science and risk: How IBSE crisis forced Europe out of its complacency, Narw'e, 385,8 .

3. Van Rensburg. DM. (1997) The phssical, chemical and senson qualin characreristics of springbok (Amidorcas marsupialis massupialis) meat, D Tecls-thesis, Technikon Pretoria, Pretoria

4. Wolmarans, P. W. (1989) The response of plasma lipoprotem leve/s to diesan? substitution of fish for red mear, M.Sc-thesis, University of the Orange Free State, Bloemfontein.

5. Mahan, L.K.. Arlin, M.T (1992). Kranse 's Food. Nmrition \& Dier Therapy: $8 / h$ ed. c. 4, 20 (W B Saunders Company. U.S.A).

6. Leat, M.D., Weber, P C. (1987). A new era for science in nutrition. Am J. ( $\mathrm{lm}$. Nutr, 45, 1048-1053

7. Sclionfeldt, H.(1993). Nurrional contem of renison. Meat Industry Centre IAPI. Forum: The Venison Industry, Research requirements \& possibilities. Unpublished report

8. Watts, G. F. Almed. W., Quiney. I. Houlston. R, lackson. P. liles, C (1988) Effective lipid lowering diets including lean meat, BMIJ. 296, 235-237

9. De Bruin, F.M(1994). Nutrinonal chatacteristics of real. M.Sc-thesis Potchefstroom University for Christian Higher Education, Potchefstroom

10. Janse van Rensburg. D M J (1999). Persoonlike mededeling deur dr lanse van Rensburg op 17 Februarie 1994, semor lekitor. Departement Voedsel en Gasvryheidsbestuur. Techunikon Preforia 